\title{
Enhanced replication of avian-origin H3N2 canine influenza virus in eggs, cell cultures and mice by a two-amino acid insertion in neuraminidase stalk
}

\author{
Yan Lin ${ }^{1,2}$, Xing Xie ${ }^{1}$, Yanbing Zhao ${ }^{1}$, Dildar Hussain Kalhoro ${ }^{1}$, Chengping Lu ${ }^{1}$ and Yongjie Liu ${ }^{1 *}$
}

\begin{abstract}
Canine influenza virus (CIV) is a newly identified, highly contagious respiratory pathogen in dogs. Recent studies indicate that avian-origin H3N2 CIV are circulating in Chinese dogs. To investigate the effects of a two-amino acid (2-aa) insertion naturally occurring at the distal end of the neuraminidase (NA) stalk found in Chinese isolates since 2010 on virus replication and virulence, we rescued the CIV strain, A/canine/Jiangsu/06/2011(H3N2) and its NA mutant without the 2-aa insertion using reverse genetics. The NA stalk length affected virus growth in cell culture. Compared to the short stalk strain (without 2-aa insertion), the long stalk strain (with 2-aa insertion) exhibited higher peak titers and greater yields in Madin-Darby canine kidney (MDCK) cells, chicken embryo fibroblasts and canine bronchiolar epithelial cells, as well as much larger plaques in MDCK cell monolayers. Furthermore, mice inoculated with the long stalk strain showed more severe pathologic damage in lung and higher proportion of detectable viral RNA in tissues. The long stalk strain induced local IFN- $\gamma$ production with faster kinetics and higher levels in mice. However, in chickens, the two viral strains showed no significant difference with nearly the same proportion of detectable viral RNA loads in tissues. These observations suggest that the 2-aa insertion in the NA stalk acquired by avian-origin H3N2 CIV helps to enhance viral replication and is likely a result of adaptive evolution in canine hosts.
\end{abstract}

\section{Introduction}

Influenza A viruses (IAV) are important pathogens in both mammalian and avian hosts, and interspecies transmission of this virus is a crucial feature of its ecology and epidemiology [1]. In 2004, an equine-origin H3N8 influenza virus was first isolated from racing greyhounds with serious respiratory disease in Florida [2]. Frequent outbreaks were subsequently reported, and the infection rapidly disseminated across the United States. In 2007, a different influenza virus, subtype H3N2, caused an outbreak of canine respiratory disease in South Korea [3]. The H3N2 CIV appeared to be entirely of avian origin, but it was able to be transmitted between dogs [4].

\footnotetext{
*Correspondence: liuyongjie@njau.edu.cn

${ }^{1}$ College of Veterinary Medicine, Nanjing Agricultural University,

Nanjing 210095, China

Full list of author information is available at the end of the article
}

The serological surveillance in South Korea and southern China showed that the seroconversion rates for $\mathrm{H} 3 \mathrm{~N} 2$ IAV were approximately 3.3 and $10 \%$, respectively, in the sampled dog population [5, 6]. These surveillance results suggest that H3N2 avian-origin CIV has become endemic in the canine populations in South Korea and China.

IAV interact with their hosts mostly through two critical glycoproteins, hemagglutinin (HA) and neuraminidase (NA). HA recognizes receptors on target cells, and NA cleaves sialic acids from receptors, preventing self-aggregation and facilitating the release of virus during budding from host cells $[7,8]$. The NA stalk region varies considerably in length, even within the same subtypes, and plays a role in replication and pathogenesis [9]. Coordination of the NA stalk with HA is known to play a significant role in virus growth and adaption to the host $[10,11]$. 
In the first few years after the outbreak in 2007, CIV isolated from South Korea and Guangdong, China, only possessed 40 amino acids (aa) in the NA stalk. However, in 2010, a 2-aa insertion was found at the distal end of the NA stalk in all six isolates from Jiangsu province, China [12]. Since then, all isolates from different provinces of China, such as Zhejiang [13], Beijing and Liaoning [14], have been shown to possess the insertion. In 2012, the insertion was also found in a Thailand H3N2 CIV isolate [15]. This genetic modification in the NA protein might be an evolutionary adaptation of avian influenza virus (AIV) to dogs. Deletions in the stalk region of NA have been found frequently in AIV in poultry [16, 17], but few studies have addressed the insertion mutations in the NA stalk as a result of virus evolution. Therefore, the aim of this study was to determine the biological properties of this 2-aa insertion generated in nature. This evolutionary change may give rise to a better understanding of the mutational frequencies associated with influenza virus replication in the canine host.

\section{Materials and methods}

\section{Virus strains, cells and medium}

A/canine/Jiangsu/06/2011(H3N2) identified from pet dogs in the Jiangsu province of China [12] was used as the wild-type canine influenza virus in this study. Primary cultures of chicken embryo fibroblasts (CEF) were prepared from specific-pathogen-free (SPF) chicken embryos (10 days old) as described previously [18]. Primary canine bronchiolar epithelial cells (CBE) was prepared from beagles according to protocols previously described [19]. Madin-Darby canine kidney (MDCK) cells, CEF cells and 293T cells were cultured in Dulbecco's modified essential medium (DMEM) whereas CBE cells were cultured in DF12, and all cells were maintained at $37^{\circ} \mathrm{C}$ and $5 \%(\mathrm{v} / \mathrm{v}) \mathrm{CO}_{2}$ atmosphere.

\section{Animals}

The 10-day-old SPF chicken embryos and SPF White Leghorn chickens (40 days old) were purchased from the Experimental Animal Center, Jiangsu Academy of Agricultural Sciences. BALB/c mice (7 weeks old, female) were purchased from the Animal Experiment Center, Yangzhou University. All animal experiments complied with the guidelines of the Animal Welfare Council of China, and approval was obtained from the Animal Ethics Committee of Nanjing Agricultural University.

\section{Sequence analysis}

The NA gene sequences of 10 reference strains of CIV from China (south, east, and northeast), South Korea and Thailand between 2007 and 2013 were compared in this study. Reference sequences were obtained from the National Center for Biotechnology Information (NCBI). Comparisons of aa sequences were made using DNASTAR software.

\section{Site-directed mutagenesis and virus generation}

A site-directed mutagenesis kit (TaKaRa, Dalian, China) was used to create specific mutation in the NA gene. H3N2 CIV with a long-stalk NA (wild-type virus) or a short-stalk NA (delNA virus) were rescued by an eightplasmid reverse genetics system as previously described [20] and designated as r-06 and r-06/NA2 virus, respectively.

\section{Replication of viruses in eggs}

Ten-day-old embryonated chicken eggs were inoculated with $200 \mu \mathrm{L}$ of virus stock serially diluted from $10^{-1}$ to $10^{-9}$ in phosphate-buffered saline (PBS). Eggs were incubated at $37{ }^{\circ} \mathrm{C}$ for $72 \mathrm{~h}$ before allantoic fluid was harvested and tested by hemagglutination (HA) assays at room temperature using $0.75 \%$ chicken RBC. Fifty-percent egg infective dose $\left(\mathrm{EID}_{50}\right)$ titers were calculated by the Reed-Muench method with eight eggs per dilution. To further measure virus quantity, plaque assays were performed on monolayers of MDCK cells in 12-well tissue culture plates. Serial dilutions were prepared from allantoic fluid collected above, and $500 \mu \mathrm{L}$ of each dilution was incubated on monolayers in duplicate for $1 \mathrm{~h}$ at $37{ }^{\circ} \mathrm{C}$ and $5 \% \mathrm{CO}_{2}$. Thereafter, the monolayers were overlaid with a mixture of $2 \%$ agarose and cell culture medium containing $0.8 \mu \mathrm{g} / \mathrm{mL}$ TPCK-treated trypsin. Cultures were incubated for 3 days at $37{ }^{\circ} \mathrm{C}$, fixed with $4 \%$ formaldehyde and stained with $1 \%$ crystal violet to reveal plaques. Experiments were performed three times with different preparation of viruses.

\section{NA activity assays}

For enzymatic assays, $50 \mu \mathrm{L}$ of a small soluble substrate 4-methylumbelliferyl $\mathrm{N}$-acetylneuraminic acid (4-MUNANA; Sigma, Beijing, China) was serially diluted in triplicate at concentrations from 5 to $120 \mu \mathrm{M}$ in black U-bottomed 96-well microtiter plates, and then $50 \mu \mathrm{L}$ virus with an equivalent titer of $2 \times 10^{5} \mathrm{pfu} / \mathrm{mL}$ was added to each well. The plates were incubated at $37{ }^{\circ} \mathrm{C}$, and UV fluorescence emission was measured every $5 \mathrm{~min}$, for $60 \mathrm{~min}$, with a 355-nm excitation filter and 460-nm emission filter. The Michaelis-Menten constant $\left(K_{\mathrm{m}}\right)$ and maximum velocity of reaction $\left(V_{\max }\right)$ were calculated by the Michaelis-Menten equation. Three different preparations of the two viruses were tested in three different experimental runs to determine the mean values. 


\section{Virus replication kinetics in cell culture}

Confluent CEF and CBE cell monolayers in 12-well tissue culture plates were inoculated with virus at the multiplicity of infection (MOI) of $0.01 \mathrm{pfu} / \mathrm{cell}$, while MDCK cells were infected with an MOI of $0.001 \mathrm{pfu} / \mathrm{cell}$. The MOI were selected on the basis of a preliminary sighting study, in which the starting MOI was screened from the fixed levels of 0.001, 0.01 and $0.1 \mathrm{pfu} / \mathrm{cell}$ as an MOI expected to examine the viral growth during $72 \mathrm{~h}$ infection process. Then all three cells were cultured with $1 \mathrm{~mL}$ DMEM with L-1-tosylamide-2-phenylethyl chloromethyl ketone (TPCK)-treated trypsin $(0.8 \mu \mathrm{g} / \mathrm{mL}$ for MDCK, and $0.15 \mu \mathrm{g} / \mathrm{mL}$ for CEF and CBE, as indicated by preliminary data). Supernatants were collected 12, 24, 36, 48, 60 and $72 \mathrm{~h}$ post-infection and titrated by plaque assay in MDCK cells. Experiments were performed three times with different preparation of viruses.

Immunofluorescence staining and flow cytometry analysis For immunofluorescence analysis, virus- or mockinfected cells in 12-well tissue culture plates were fixed with $4 \%$ paraformaldehyde in PBS at room temperature for 20 min, after which cells were washed with PBS and permeabilized in $0.2 \%$ Triton $\mathrm{X}-100$ at room temperature for $5 \mathrm{~min}$. Cells were then incubated at $37^{\circ} \mathrm{C}$ for $1 \mathrm{~h}$ with rabbit anti-NS1 protein polyclonal serum (prepared in our laboratory using purified NS1 protein) diluted $1 / 1000$ in PBS. Cells were washed with PBS and incubated with secondary FITC-labeled goat anti-rabbit antibodies (Dingguo, Beijing, China) diluted 1/500 in PBS at $37^{\circ} \mathrm{C}$ for $1 \mathrm{~h}$. After three washes with PBS, the cells were observed with a fluorescence microscope.

For flow cytometry, virus- or mock-infected cells were digested with $0.25 \%$ trypsin-EDTA solution from the tissue culture flask, followed by incubation at $37^{\circ} \mathrm{C}$ for $1 \mathrm{~h}$ with rabbit anti-NS1 protein polyclonal serum. The subsequent steps were carried out in the same manner as for the immunofluorescence analysis. Finally, flow cytometric analysis was performed using an Accuri C6 flow cytometer (BD Accuri) and analyzed using CFlow plus software (Accuri). Three different preparations of the two viruses were tested in three different experimental runs to determine the mean values.

\section{Experimental infections in mice and chickens}

In the mouse experiment, intranasal inoculations were given to group I $(n=30)$ with $\mathrm{r}-06$ strain, group II $(n=30)$ with $\mathrm{r}-06 / \mathrm{NA} 2$ strain and group III $(n=30)$ with PBS. A total volume of $50 \mu \mathrm{L}$ of the virus stock was inoculated per mouse with a viral titer of $2 \times 10^{6} \mathrm{pfu} / \mathrm{mL}$. The percent of body weight change was calculated from body weights of 10 mice recorded daily after infection relative to that at day 0 (pre-infection). Five mice from each group were euthanized humanely according to a pre-designated schedule. At each of the time points of 2 , 4, 6, 8 and 14 days post-infection (dpi), tissues including lung, brain, heart, spleen, liver, intestine and kidney as well as feces were collected.

In the chicken experiment, 3 groups of 20 SPF White Leghorn chickens were intranasally inoculated with a viral titer of $2 \times 10^{6} \mathrm{pfu} / \mathrm{mL} \mathrm{r-06,r-06/NA2} \mathrm{viruses} \mathrm{or}$ PBS in a volume of $100 \mu \mathrm{L}$. The percent of body weight change was calculated from body weights recorded daily after infection relative to that at day 0 (pre-infection). Five chickens were chosen randomly on 2, 5, 9 and 14 dpi from each group and euthanized humanely. The oropharyngeal and cloacal swabs, heart, liver, spleen, lung, kidney, brain, intestine and pectoralis were collected for virus detection.

\section{Histopathologic evaluation of lungs}

Histopathology was performed as described previously [12]. Lung sections were blindly examined and given an estimated score of the severity of the interstitial pneumonia: $0=$ no microscopic lesions; $1=$ mild interstitial pneumonia and $<10 \%$ of the lung affected; $2=$ moderate multifocal interstitial pneumonia and $10-40 \%$ of the lung affected; $3=$ severe interstitial pneumonia and $>40 \%$ of the lung affected. In section of each mouse, 2 fields were randomly selected for evaluation. Lungs of all five mice from $6 \mathrm{dpi}$ and five chickens from $5 \mathrm{dpi}$ of two infected groups were examined.

\section{Immunohistochemistry and quantitative assessment of immunostaining}

Immunohistochemistry on sections from the lung, spleen and brain was performed as described previously [12]. Tissue sections were blindly examined and given an estimated score of the immunostaining. In the lung and spleen, the extent of the staining was semi-quantitatively scored on a scale of 0 to 3 . Score criteria of different scales were assigned based on the percentage of positive staining per examined area: $0,<10 \% ; 1,10-30 \%$; $2,30-60 \% ; 3,>60 \%$. The intensities of the signals were graded as $1+$ (weak), $2+$ (intermediate), and $3+$ (strong). Then, a combined score (0-9) for each section was calculated by multiplying the values of these two categories [21]. Cases were classified as negative, 0 points, positive, 1-9 points. In the brain, at least 600 cells (from 3 independent experiments, 200 cells/each) manually counted and the percentage of the positively stained cells was calculated. In each tissue specimen from each mouse, three fields were randomly selected for evaluation. All five mice from $6 \mathrm{dpi}$ of two infected groups were examined. 


\section{Quantitation of viral loads and cytokine levels}

Tissues and feces were homogenized in PBS at a ratio of $1: 5(\mathrm{~g} / \mathrm{mL})$ and centrifuged at $10000 \times g$ for $30 \mathrm{~min}$. The supernatants were collected for the extraction of viral RNA with the Virus Nucleic Acid Extraction Kit II (Geneaid, Taiwan). Real-time PCR for quantitation of viral loads was performed as described previously [12]. The set of primers was designed based on the region of the matrix gene as follows: TCTATCGTCCCATCAGGC/GGTCTTGTCTTTAGCCATTC. The data were normalised per gram. In addition, supernatants of lung tissue from mice and chickens were also used for the analysis of IFN- $\gamma$ and TNF- $\alpha$ using the commercially available ELISA kits (Jiancheng, Nanjing, China).

\section{Statistical analysis}

All statistical analyses were performed with Prism 5 software (GraphPad). Data are expressed as arithmetic means \pm standard deviations. Comparisons between the two experimental groups were made by a Student's $t$ test with two-tailed analysis, but cytokine data among control and two experimental groups were analyzed using oneway ANOVA with a Bonferroni multiple-comparison test. $P$ values of less than 0.05 were considered statistically significant [22].

\section{Results}

\section{Sequence alignment of NA stalk region of H3N2 CIV} from different geographical areas

The NA stalk sequences of reference strains were obtained from NCBI, and their accession numbers are listed in Figure 1 . The alignment of the stalk region shows that H3N2 CIV from South Korea and Guangdong, China, in 2007 contained only 40 aa in the NA stalk. However, a 2 -aa insertion at the distal end of the NA stalk was found widely in viruses isolated from eastern and northeastern China since 2010. In 2012, strains were reported in Guangdong with 1- or 2-aa insertions in NA. Curiously, until 2012, no insertion in the NA stalk was reported in
South Korean H3N2 CIV, whereas Thailand had reported a case of an H3N2 CIV containing the insertion (Figure 1).

\section{Generation of viruses by reverse genetics and their growth in MDCK cells and eggs}

To determine whether the two amino acids naturally occurring as inserts in 06 influence viral yield, we rescued the Jiangsu 06 virus ( $\mathrm{r}-06)$ and its NA mutant with the 2 -aa deletion at the distal end of the NA stalk (r-06/NA2). Reassortant viruses were verified by RT-PCR, followed by sequencing of the NA gene and seven other gene segments to confirm there was no other mutation except the 22-aa deletion in NA genes of r-06/NA2 virus.

Growth characteristics of rescued viruses were analyzed in MDCK cells. It was apparent that r-06/NA2 without the 2-aa insertion formed small pin-point plaques on MDCK cell monolayers at $72 \mathrm{~h}$ after inoculation, while the $\mathrm{r}-06$ strain made much larger plaques than did the r-06/NA strain (Figure 2). The r-06/NA2 strain formed plaques after $48 \mathrm{~h}$, whereas the r-06 strain formed plaques after only $36 \mathrm{~h}$.

Growth characteristics of rescued viruses were also compared in eggs using an $\operatorname{EID}_{50}$ experiment performed with the same viral titer of $2 \times 10^{6} \mathrm{pfu} / \mathrm{mL}$. The $\mathrm{EID}_{50}$ titer of $\mathrm{r}-06$ was not statistically different from that of $\mathrm{r}-06 / \mathrm{NA} 2\left(10^{-7.020} \pm 0.098 / 200 \mu \mathrm{L}\right.$ versus $\left.10^{-6.793} \pm 0.104 / 200 \mu \mathrm{L}, P>0.05\right)$. However, notably, the HA titer of $\mathrm{r}-06$ was significantly higher than that of r-06/NA2 $\left(2^{-7.260 \pm 0.061}\right.$ versus $\left.2^{-5.950 \pm 0.038}, P<0.0001\right)$ by analysis of allantoic fluid from all infected eggs with $10^{-3}-10^{-5}$ dilutions of the two viruses. Further, we measured plaque forming unit (PFU) counts of the two viruses in the above allantoic fluid using a plaque assay. Similar to an HA titer, the PFU value of $\mathrm{r}-06$ was also 2-4 times higher than that of $\mathrm{r}-06 / \mathrm{NA} 2\left(10^{6.318} \pm 0.087 \mathrm{pfu} / \mathrm{mL}\right.$ versus $\left.10^{5.835 \pm 0.120} \mathrm{pfu} / \mathrm{mL}, P=0.031\right)$. The findings suggest that the 2-aa insertion in the NA stalk did not significantly change virus virulence in eggs, but increased virus yield in eggs.

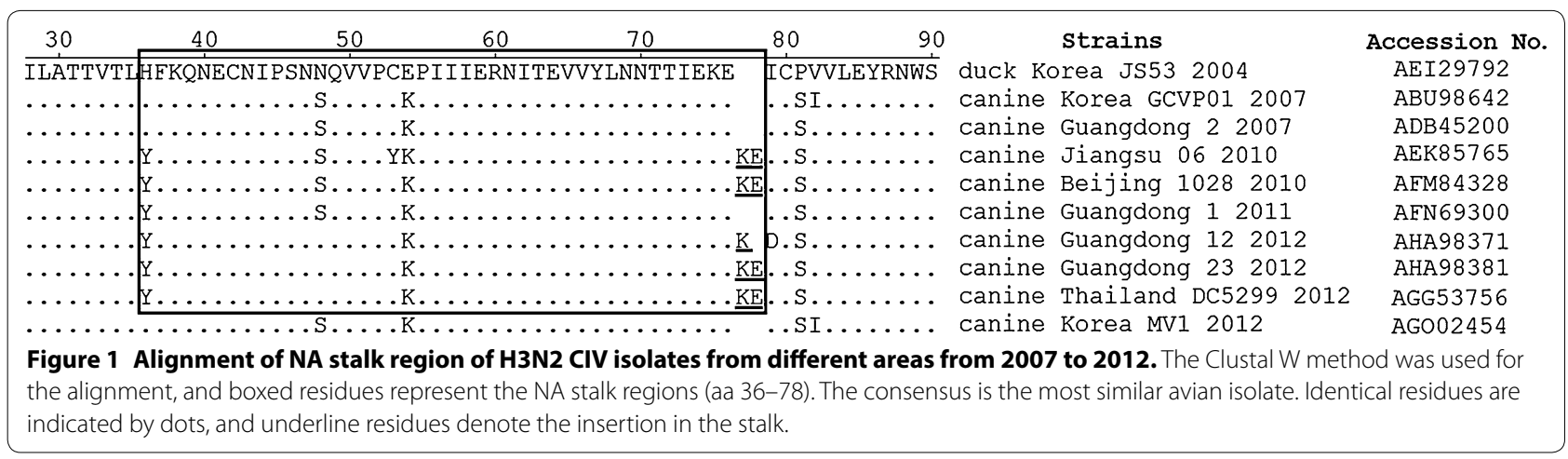




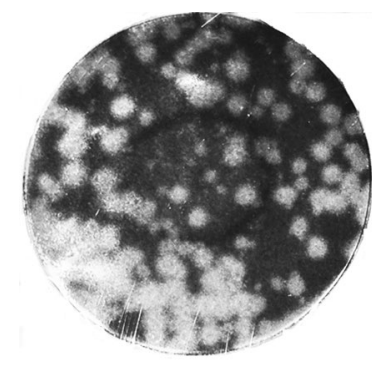

r-06

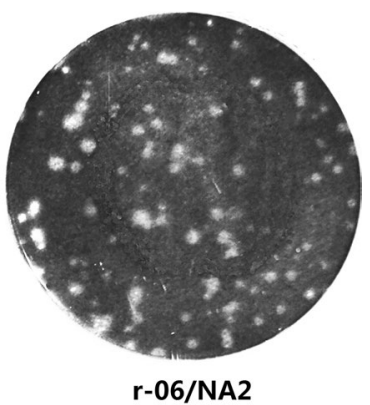

r-06/NA2
Figure 2 Plaque morphology of r-06 and r-06/NA2 strains grown in MDCK cell monolayers. Cells were infected at an $\mathrm{MOI}$ of 0.001 and cell monolayers were fixed with formaldehyde at $72 \mathrm{~h}$ postinfection and stained with $1 \%$ crystal violet.

\section{Replication kinetics of $\mathrm{r}-06$ and $\mathrm{r}-06 / \mathrm{NA} 2$ viruses in cell cultures}

CEF and CBE cells were infected at the MOI of 0.01, which was 10-fold higher than that used to infect the MDCK cells (Figure 3). In MDCK cells, the r-06 strain had significantly higher virus yields at most time points. In CEF cells, r-06 strain reached the peak viral titer at $36 \mathrm{~h}, 12 \mathrm{~h}$ earlier than the r-06/NA2 strain did, and the r-06 strain had significantly higher virus yields at most of time points as well. In CBE cells, the r-06 strain reached the peak viral titer at $36 \mathrm{~h}$ whereas the r-06/NA2 strain did at $60 \mathrm{~h}$. And the r-06 strain had significantly higher virus yields at three time points: 36, 48 and $60 \mathrm{~h}$. Taken together, our data show that the r-06 strain had a higher replicative capacity than the $\mathrm{r}-06 / \mathrm{NA} 2$ strain in cell culture.

\section{Infectivity efficiency of r-06 and r-06/NA2 viruses in cell cultures}

To evaluate the virus infectivity efficiency, viral NS1 expression was determined at $24 \mathrm{~h}$ after infection by immunofluorescence microscopy using an anti-NS1 antibody in all three cell lines. We inoculated confluent cell monolayers with $\mathrm{r}-06$ or $\mathrm{r}-06 / \mathrm{NA} 2$ viruses, and positive cells exhibited green staining. From Figure 4A, we can see that in all three cells, stronger fluorescence was observed in r-06-infected cells than r-06/NA2-infected cells. Especially in MDCK cells, $\mathrm{r}-06$ infection resulted in a noticeably greater number of stained cells than r-06/NA2 infection.

For quantification of the NS1-positive rate (\%) and the mean fluorescence intensity (MFI) of NS1 expression in the $\mathrm{NS}^{+}$population, the three cell cultures infected with the two viral strains were subjected to flow cytometry (Figure 4B). NS1 expression was calculated by fold MFI of mock-infected cells. The proportion of r-06-infected MDCK cells $\left(\mathrm{CIV} \mathrm{NS1}{ }^{+}\right)$was $53.28 \pm 3.46 \%$, which was statistically significantly $(P=0.0097)$ higher than the proportion of $\mathrm{r}-06 / \mathrm{NA} 2$-infected cells $(39.73 \pm 1.08 \%)$ being consistent with the results obtained by immunofluorescence microscopy. Likewise, NS1 expression in r-06 infected cells was $6.327 \pm 0.4923$ times higher than that of mock-infected cells whereas r-06/NA2 infected cells was only $4.355 \pm 0.0746$ times higher $(P=0.0167)$. In CEF cells, the r-06 strain infected more cells than did the $\mathrm{r}-06 / \mathrm{NA} 2$ strain $(59.77 \pm 1.828 \%$ versus $51.50 \pm 1.665 \%$, $P=0.0288)$, as well as NS1 expression (28.94 \pm 1.592 versus $17.89 \pm 1.282$ times, $P=0.0057)$. Interestingly, although the ratios of CBE cells infected by the two viral strains were similar, the NS1 expression levels were statistically significantly different $(2658 \pm 143.8$ versus $1681 \pm 81.15$ times, $P=0.0041$ ), being higher with $r-06$ infection (Figures $4 \mathrm{C}$ and $\mathrm{D}$ ). Although the viral titer was the highest in MDCK cells, MFI of infected MDCK cells was fewer folds of mock infected cells than that of CEF or CBE cells. This phenomenon may be explained by the substantially much higher background staining for the MDCK cells. As we can see from Figure 4B, the MFI of mock-infected MDCK cells was $10^{4.5}$, while the MFI of mock-infected CEF or CBE cells was $10^{3}$.

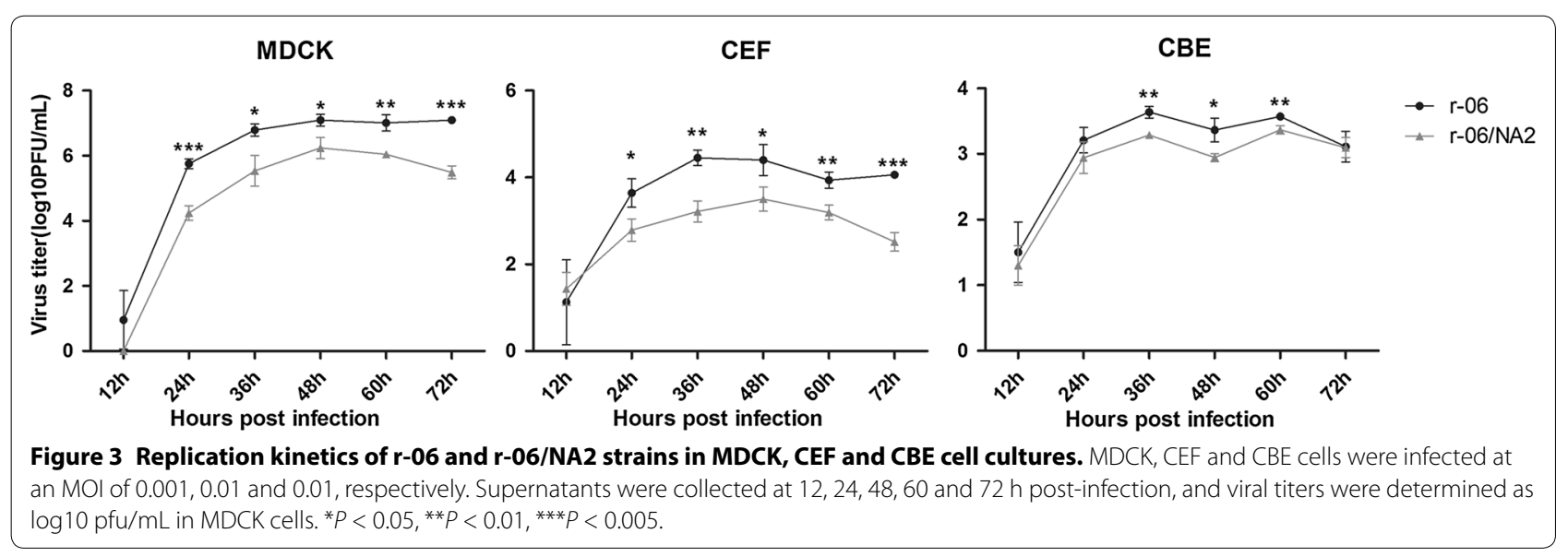



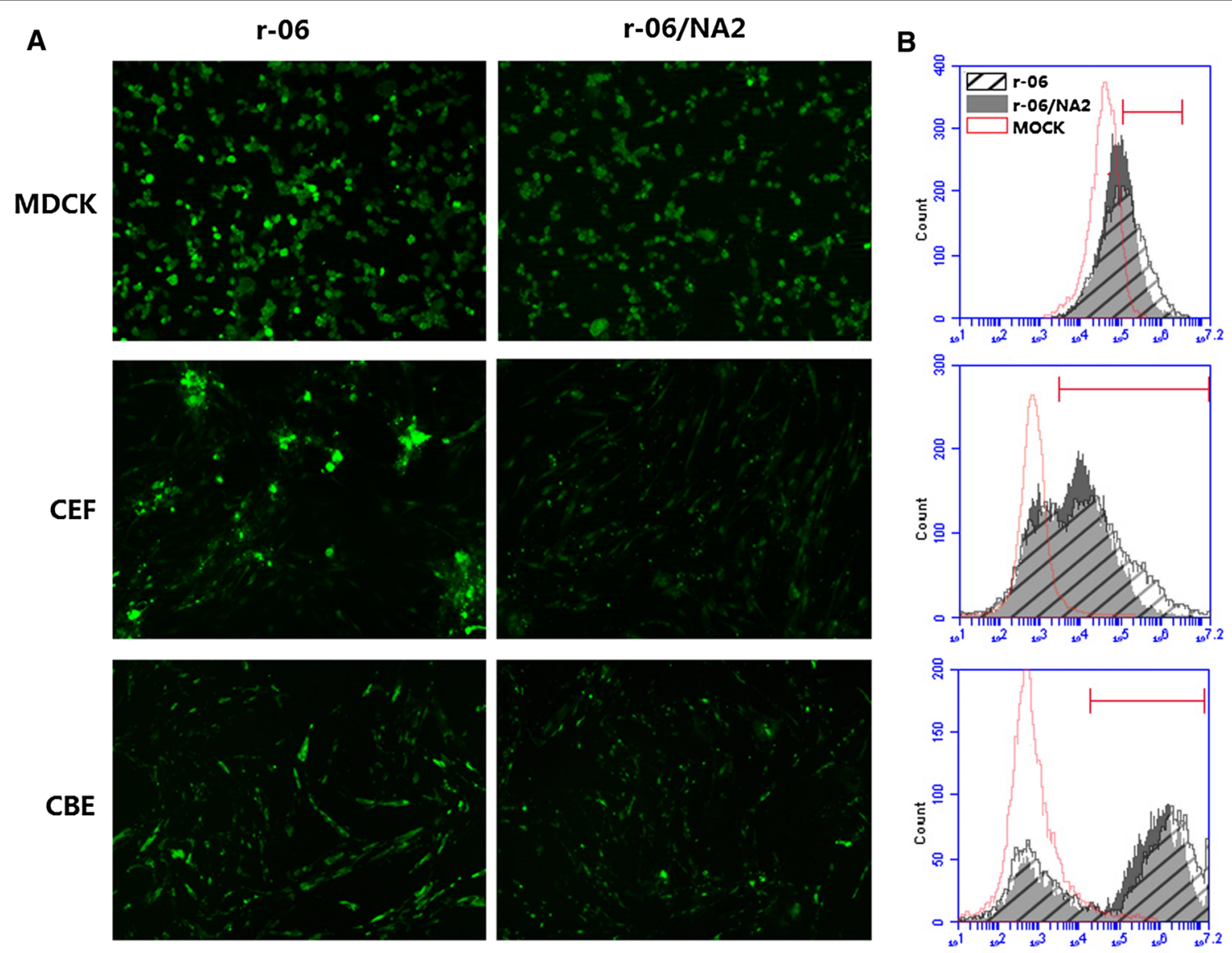

C
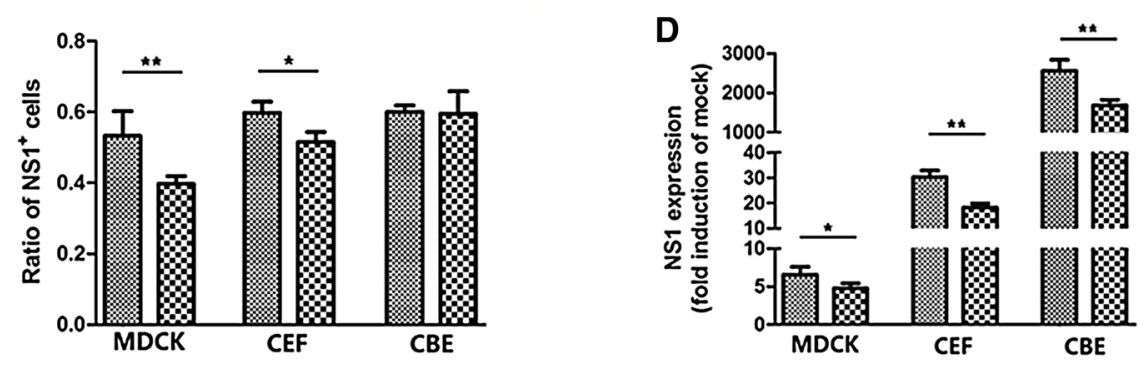

Figure 4 Replication of $\mathbf{r - 0 6}$ and r-06/NA2 strains in MDCK, CEF and CBE cell cultures. MDCK, CEF and CBE cells were infected with the two viruses at an $\mathrm{MOI}$ of $0.001,0.01$ and 0.01 , respectively, and the viral NS1 expression was determined at $24 \mathrm{~h}$ after infection by immunofluorescence microscopy using an anti-NS1 antibody. A Indirect immunofluorescence staining of infected cells. B FACS analysis of infected cells. Red bar indicates the positive region. The infected cells in which fluorescence intensities (FIs) were larger than those in mock infected cells were confirmed as positive (right part of the mock histogram, red bar region). The area of red bar region represents the count of NS1 ${ }^{+}$cells. C Quantification of the NS1 ${ }^{+}$ proportion of infected cells in FACS analysis. NS1 ${ }^{+}$ratio was calculated by the proportion of cells of red bar region in all cells by CFlow plus software. D Quantification of NS1 expression by mean fluorescence intensities (MFIs) in FACS analysis. NS1 expression is depicted as fold MFI of mock-infected cells. MFIs of $\mathrm{NS}^{+}$cells (in red bar region) were calculated by CFlow plus software. ${ }^{*} P<0.05,{ }^{*} P<0.01$.

\section{Enzymatic activity of NA of r-06 and r-06/NA2 viruses}

To determine if the enzymatic properties of NA was affected by the 2-aa insertion in the NA stalk, we tested the NA activity against the single-valent substrate 4-MU-NANA and multivalent RBC substrate. The Km value that reflects affinity for the substrate showed no significant difference between r-06 and r-06/NA2 strains (7.884 \pm 2.734 versus $4.815 \pm 1.092 \mu \mathrm{M}, P=0.356)$. However, the $V \max$ value, which is determined by both the specific activity and the amount of enzyme in the reaction, was significantly higher in the r-06 strain as compared to the r-06/NA2 strain $(28.31 \pm 2.726$ versus 
$14.81 \pm 0.0926 \mathrm{FU} / \mathrm{s}, P=0.009)$. The results indicate that the 2-aa insertion in the NA stalk could increase enzymatic activity.

\section{Virulence of $\mathrm{r}-06$ and $\mathrm{r}-06 / \mathrm{NA2}$ viruses in mice}

In order to assess the differences in the pathogenicity of virus strains in mice, weight loss, viral loads in tissues and cytokine levels were compared. A total volume of $50 \mu \mathrm{L}$ of the virus stock was inoculated per mouse with a viral titer of $2 \times 10^{6} \mathrm{pfu} / \mathrm{mL}$. Mice infected with the r-06 strain lost more body weight than those infected with r-06/NA2 during the challenge, especially at $2,6,7$ and 8 dpi $(P=0.025, P=0.014, P=0.031, P=0.038$, respectively) (Figure 5).

A real-time PCR assay was performed to determine viral loads in the main tissues from CIV-infected mice. By $2 \mathrm{dpi}$, in both groups, virus had begun to shed in the feces and to replicate in the lung and intestine. By $4 \mathrm{dpi}$, the r-06 virus was detected in all tissues, whereas the r-06/NA2 virus could not be detected in the liver, kidney and brain. By $6 \mathrm{dpi}$, both infected groups had a high proportion of animals $(5 / 5)$ with detectable viral RNA in all tested tissues. By 8 dpi, r-06 infected mice still exhibited a high level of detectable viral RNA in tissues, whereas r-06/NA2 infected mice showed a reduction. By $14 \mathrm{dpi}$, both groups presented signs of recovery, with some tissues having an undetectable virus level, however, $r$-06-infected mice showed fewer tissues cleared of virus. No viral RNA was detected in any tissues of mice from the control group (Table 1).

Further, we compared viral RNA loads of tested tissues and fecal samples at 6 and 8 dpi (Figure 6). As shown in Figure 6A, at $6 \mathrm{dpi}$, viral RNA titers of spleen $(P=0.0357)$, lung $(P=0.0168)$, and brain $(P=0.0419)$

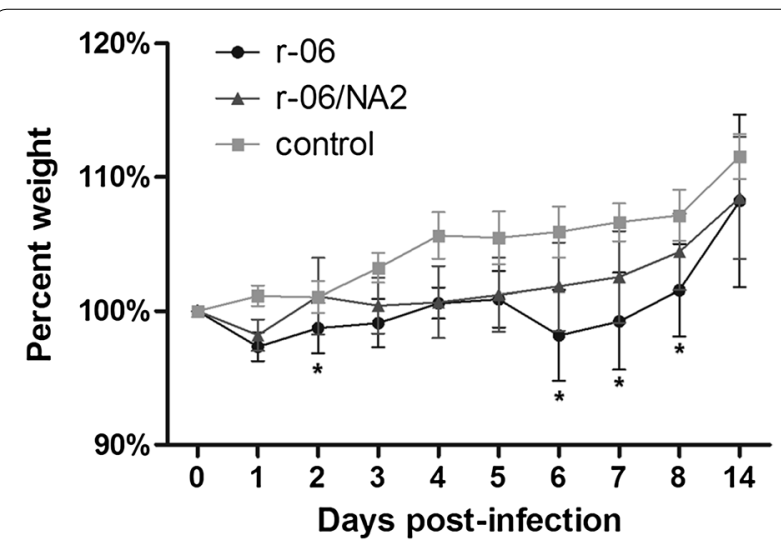

Figure 5 Changes in body weight of BALB/c mice after inoculation with influenza virus strains $r-06$ ( $)$ and r-06/NA2 (and PBS as control ( ). The percent of body weight change was calculated from body weights of 10 mice recorded daily after infection relative to that at day 0 (pre-infection). ${ }^{*} P<0.05$ in the r-06-infected group were significantly higher than those in the r-06/NA2-infected group. At $8 \mathrm{dpi}$, viral RNA loads in all tissues from both infected groups were decreased as compared to those at $6 \mathrm{dpi}$, and r-06-infected mice appeared to have higher mean viral RNA loads in the detectable tissues than those of r-06/NA2-infected mice (Figure 6B). However, statistical analysis could not be performed because of an insufficient number $(<3)$ of the detectable tissues in r-06/NA2-infected mice at $8 \mathrm{dpi}$.

Considering that significantly higher viral RNA loads were detected in the lung, spleen and brain of $\mathrm{r}-06$ infected mice, a quantitative assessment of immunostaining in the three tissues was performed for further verification of virus infection. In the lung and spleen, viral antigens could be detected in both infected groups, but compared to the r-06/NA2 group, significantly higher immunochemistry scores were observed in the r-06 group $(P=0.015$ in lung and $P=0.025$ in spleen, respectively). In the brain, antigen staining was much less than that in the lung and spleen from both infected groups, however, the percentage of positively stained cells in r-06-infected mice was still higher than that of r-06/NA2infected mice $(P=0.045)$ (Figure 7).

Histological lesions in the lungs were evaluated at 6 dpi. In r-06 or r-06/NA2-infected mice, interstitial pneumonia was obvious with the alveolar septum thickened by the infiltration of a number of inflammatory cells (Figure 8). However, r-06-infected mice showed larger areas of thickened alveolar septum. The pathological score of the lungs of $\mathrm{r}$-06-infected mice was $2.417 \pm 0.229$, significantly higher $(P=0.0318)$ than that of r-06/NA2-infected mice (1.750 \pm 0.179$)$.

To further investigate if the two viral strains induced different immune responses, we determined the levels of two T helper type 1 (Th1) cytokines, IFN- $\gamma$ and TNF- $\alpha$, which both exert strong antiviral activity against influenza viruses. Both infected groups had statistically significantly higher levels of IFN- $\gamma$ as compared to the control group at all time points, with a gradual increasing trend from 2 to $6 \mathrm{dpi}$. At $2 \mathrm{dpi}$, the $\mathrm{r}-06$ infection promoted significantly higher levels of IFN- $\gamma$ than $\mathrm{r}-06 / \mathrm{NA} 2$ did $(P=0.027)$, while both infected groups had the similar IFN- $\gamma$ levels at 4 dpi and $6 \mathrm{dpi}$. At $8 \mathrm{dpi}$, the $\mathrm{r}-06$ infected group still kept a higher level of IFN- $\gamma$ while r-06/NA2 infected group had a decreasing trend, and IFN- $\gamma$ levels in the r-06 group were significantly higher than those in the $r-06 / N A 2$ group $(P=0.023)$. For TNF- $\alpha$, the two infected groups had statistically significantly higher levels than the control group at 2, 4 and $6 \mathrm{dpi}$, and then had reduced levels comparable to that of the control group at 8 dpi. No obvious difference was observed between the two infected groups in the level of TNF- $\alpha$ at any time point (Figure 9). 
Table 1 Proportion of mice in which viral RNA was detectable in samples

\begin{tabular}{|c|c|c|c|c|c|c|c|c|}
\hline \multirow[t]{2}{*}{ Days post-infection (dpi) } & \multicolumn{8}{|c|}{ Proportion of mice with detectable viral RNA ( $r-06, r-06 / N A 2)$} \\
\hline & Heart & Liver & Spleen & Lung & Kidney & Brain & Intestine & Feces \\
\hline 2 & $0 / 5,0 / 5$ & $0 / 5,1 / 5$ & $0 / 5,0 / 5$ & $4 / 5,1 / 5$ & $0 / 5,0 / 5$ & $0 / 5,0 / 5$ & $1 / 5,2 / 5$ & $2 / 5,1 / 5$ \\
\hline 4 & $2 / 5,2 / 5$ & $1 / 5,0 / 5$ & $2 / 5,1 / 5$ & $5 / 5,2 / 5$ & $1 / 5,0 / 5$ & $2 / 5,0 / 5$ & $4 / 5,3 / 5$ & $3 / 5,3 / 5$ \\
\hline 6 & $5 / 5,5 / 5$ & $5 / 5,5 / 5$ & $5 / 5,5 / 5$ & $5 / 5,5 / 5$ & $5 / 5,5 / 5$ & $5 / 5,5 / 5$ & $5 / 5,5 / 5$ & $5 / 5,5 / 5$ \\
\hline 8 & $5 / 5,3 / 5$ & $4 / 5,1 / 5$ & $4 / 5,2 / 5$ & $4 / 5,3 / 5$ & $4 / 5,1 / 5$ & $4 / 5,3 / 5$ & $4 / 5,3 / 5$ & $4 / 5,2 / 5$ \\
\hline 14 & $3 / 5,1 / 5$ & $1 / 5,0 / 5$ & $1 / 5,0 / 5$ & $2 / 5,1 / 5$ & $0 / 5,0 / 5$ & $0 / 5,0 / 5$ & $1 / 5,1 / 5$ & $1 / 5,1 / 5$ \\
\hline
\end{tabular}

The data represent the results obtained from the mice inoculated with $\mathrm{r}-06$ and $\mathrm{r}-06 / \mathrm{NA} 2$ strains, respectively.

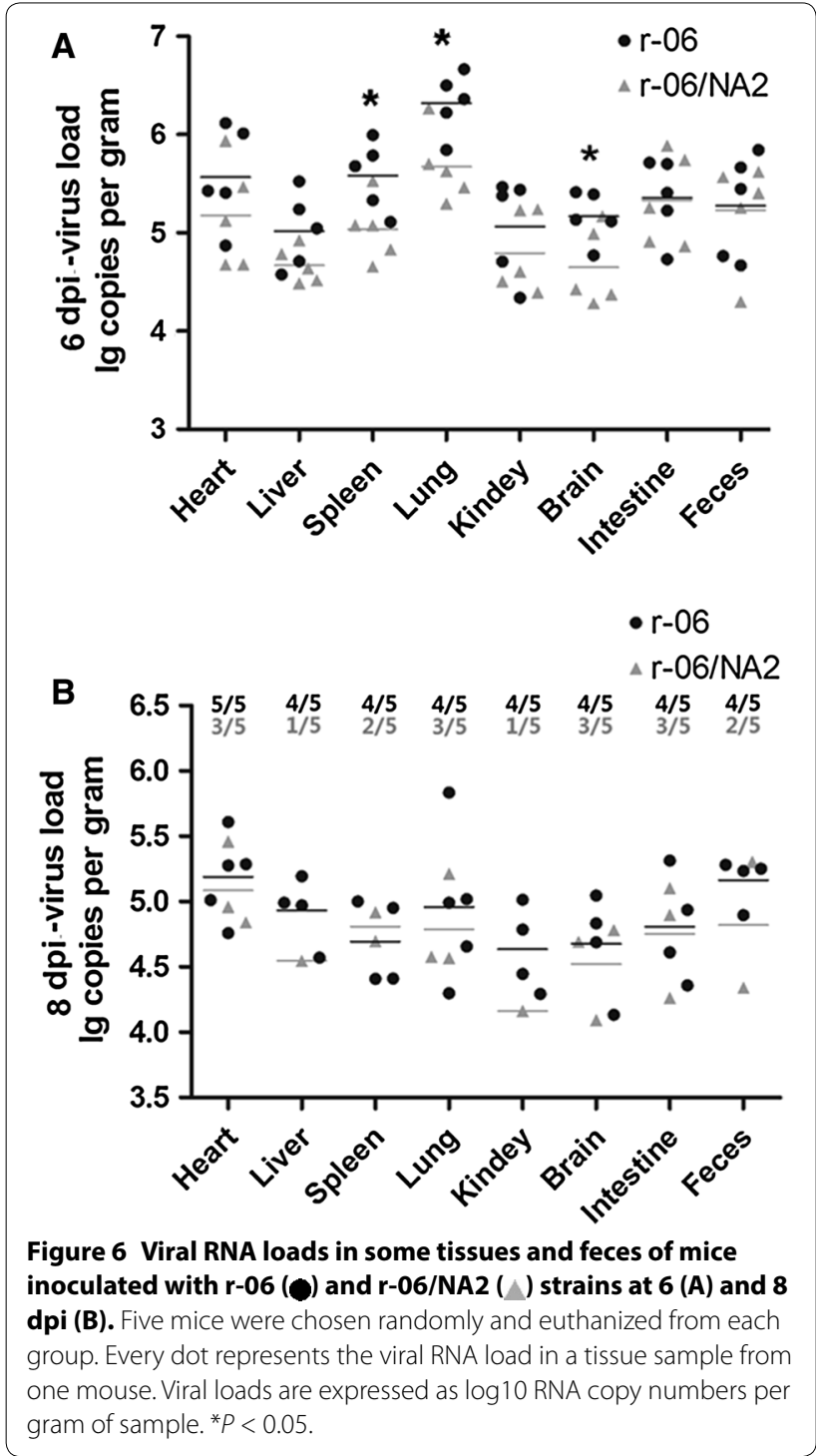

Virulence of r-06 and r-06/NA2 viruses in chickens

To investigate whether the 2-aa insertion in the NA stalk would influence virus infectivity in SPF chickens, two groups of animals were inoculated intranasally with 100 $\mu \mathrm{L}\left(2 \times 10^{6} \mathrm{pfu} / \mathrm{mL}\right)$ of $\mathrm{r}-06$ or $\mathrm{r}-06 / \mathrm{NA} 2$ virus. As with the mouse infection experiment, we compared the results of body weight loss and viral RNA loads in various tissues and from oropharyngeal and cloacal swabs. Animals of both infected groups showed no clinical symptoms but grew more slowly than those of the control group, with reductions to the minimum weight at $3 \mathrm{dpi}$. The r-06/ NA2-infected chickens grew more slowly over the first 6 days but faster from 7 dpi than r-06-infected chickens, but the differences between the two infected groups did not reach the statistical significance $(P>0.05)$ during the challenge period.

We found that in both infected groups the highest proportion of detectable viral RNA in organs and the widest range of tissue distribution were at $2 \mathrm{dpi}$. Additionally, the proportion of viral RNA positive organs in both groups decreased from $5 \mathrm{dpi}$, and the distribution range was reduced from $9 \mathrm{dpi}$. By $14 \mathrm{dpi}$, viral RNA could be detected in very few organs at a very low level. There were no apparent differences between the two viral strains in tissue distribution and proportion of tissues positive for viral RNA. A high rate (5/5) of viral RNA was detected at 2, 5 and 9 dpi in oropharyngeal swabs in both groups, and this frequency decreased (3/5) at $14 \mathrm{dpi}$. The virus-positive proportion in oropharyngeal swabs was higher than those in tissues (Table 2).

We compared viral RNA loads in different tissues at 2 dpi since the widest range of tissue distribution and highest proportion of detectable viral RNA in tested tissues were found at that time point. Viral loads showed no significant differences between the two infected groups (Figure 10).

At $5 \mathrm{dpi}$, the lungs of the infected chickens were histologically characterized by interstitial pneumonia, similar to what had been observed in mice. However, the difference in the pathological scores of the lungs did not reach statistical significance between the two infected groups.

We also determined the levels of IFN- $\gamma$ and TNF- $\alpha$ in chickens (Figure 11). Both infected groups showed statistically significantly higher levels $(P<0.05)$ of IFN- $\gamma$ than the control group at 2, 5 and 9 dpi. For TNF- $\alpha$, although 

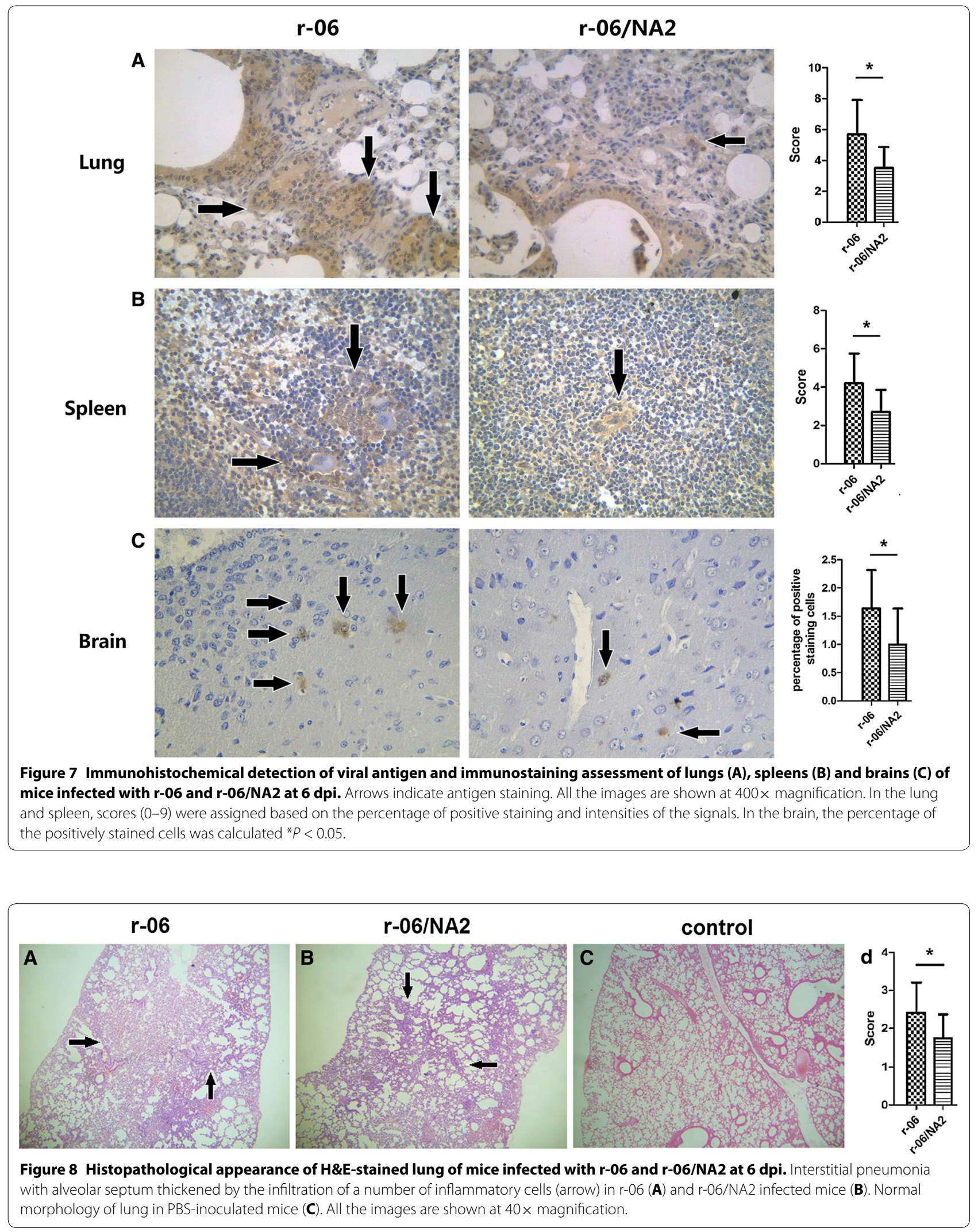


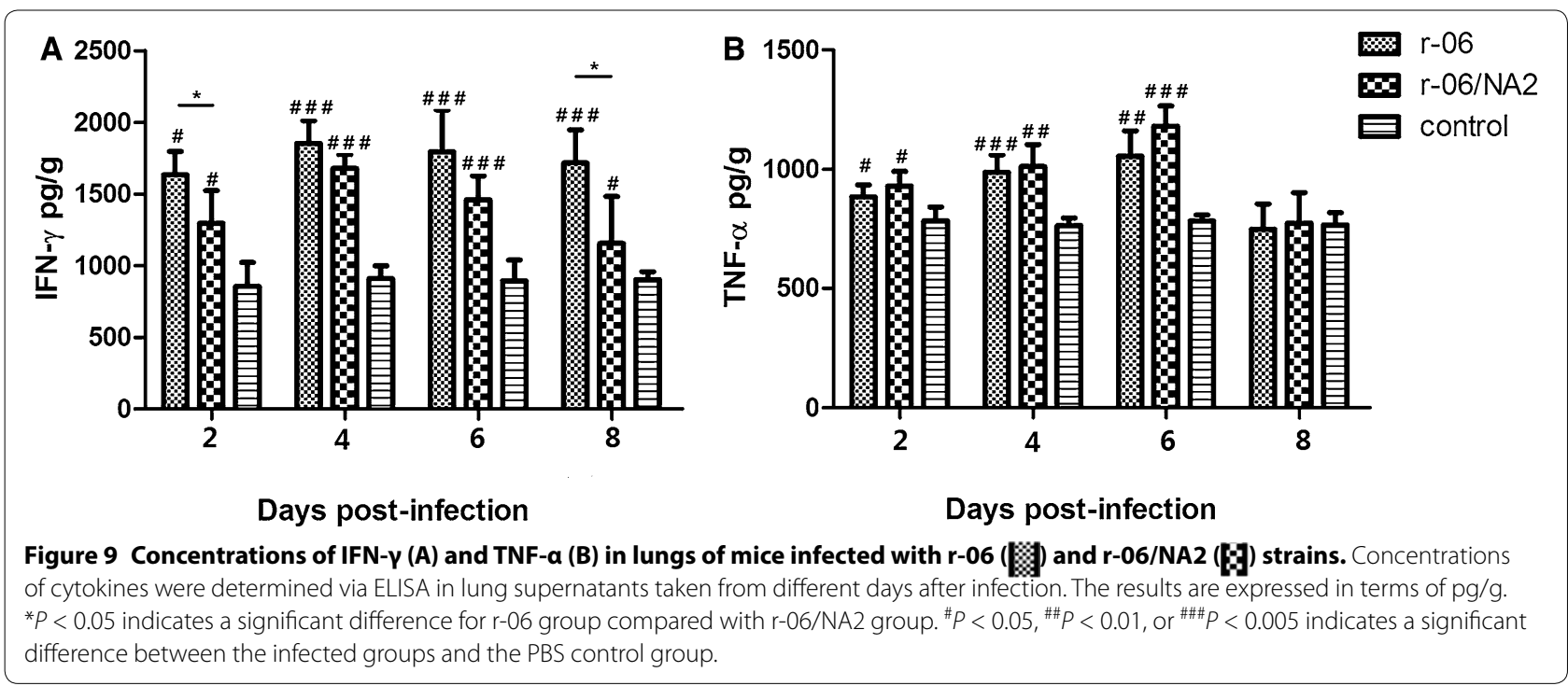

Table 2 Proportion of chickens in which viral RNA was detectable in samples

\begin{tabular}{|c|c|c|c|c|c|c|c|c|c|c|}
\hline \multirow{2}{*}{$\begin{array}{l}\text { Days post-infection } \\
\text { (dpi) }\end{array}$} & \multicolumn{10}{|c|}{ Proportion of chickens with detectable viral RNA (r-06, r-06/NA2) } \\
\hline & Heart & Liver & Spleen & Lung & Kidney & Brain & Intestine & Pectoralis & Oropharyngeal swab & Cloacal swab \\
\hline 2 & $5 / 5 ; 5 / 5$ & $2 / 5 ; 3 / 5$ & $5 / 5 ; 5 / 5$ & $4 / 5 ; 4 / 5$ & $5 / 5 ; 5 / 5$ & $5 / 5 ; 2 / 5$ & $3 / 5 ; 2 / 5$ & $5 / 5 ; 3 / 5$ & $5 / 5,5 / 5$ & $2 / 5,2 / 5$ \\
\hline 5 & $3 / 5 ; 4 / 5$ & $3 / 5 ; 3 / 5$ & $2 / 5 ; 4 / 5$ & $0 / 5 ; 1 / 5$ & $1 / 5 ; 2 / 5$ & $2 / 5 ; 3 / 5$ & $1 / 5 ; 1 / 5$ & $3 / 5 ; 4 / 5$ & $5 / 5,5 / 5$ & $1 / 5,1 / 5$ \\
\hline 9 & $2 / 5 ; 1 / 5$ & $1 / 5 ; 2 / 5$ & $2 / 5 ; 2 / 5$ & 0/5;0/5 & $2 / 5 ; 0 / 5$ & $1 / 5 ; 2 / 5$ & $0 / 5 ; 1 / 5$ & $2 / 5 ; 2 / 5$ & $5 / 5,5 / 5$ & $0 / 5,0 / 5$ \\
\hline 14 & $1 / 5 ; 0 / 5$ & $1 / 5 ; 1 / 5$ & $1 / 5 ; 1 / 5$ & $1 / 5 ; 1 / 5$ & 0/5;0/5 & $0 / 5 ; 1 / 5$ & $0 / 5 ; 0 / 5$ & $1 / 5 ; 0 / 5$ & $3 / 5,3 / 5$ & $0 / 5,0 / 5$ \\
\hline
\end{tabular}

The data represent the results obtained from the chickens inoculated with r-06 and r-06/NA2 strains, respectively.

both virus infection groups exhibited higher levels than the control group at 2 and $5 \mathrm{dpi}$, the difference did not reach statistical significance $(P>0.05)$. In comparing the two infected groups, the r-06 group showed higher levels of IFN- $\gamma$ and TNF- $\alpha$ than the $r-06 / N A 2$ group at 2, 5, and $9 \mathrm{dpi}$, but no statistically significant difference was found $(P>0.05)$.

The sera of euthanized chickens were HI-tested for evidence of seroconversion on each scheduled day, and no difference was found between the two infected groups. Chickens of both groups showed no seroconversion $(0 / 5)$ at $5 \mathrm{dpi}$, but all chickens had seroconverted (5/5) by $9 \mathrm{dpi}$ with HI titers ranging from $2^{2}-2^{4}$.

\section{Discussion}

CIV is a newly identified, highly contagious respiratory pathogen of dogs. To date, H3N2 CIV have been reported across Asia. Our previous study found that several common mutations occurred at the receptor-binding sites, potential glycosylation sites and cleavage site in $\mathrm{HA}$, and antigenic sites in both the HA and NA segments upon the initial interspecies transmission of H3N2 AIV to dogs [12]. In the following years, when H3N2 CIV were sequentially isolated in China, no important new common mutation occurred in $\mathrm{HA}$, whereas a common 2-aa insertion in the NA stalk was found in all isolates in eastern and northern China since 2010. In particular, CIV in Guangdong showed an interesting pattern in that no insertion was detected from 2006 to 2011, and then one insertion and two insertions were found separately in 2012. Thus, NA of H3N2 CIV in Guangdong seemed to evolve from 2006 to 2012. NA is generally known to exhibit lower mutation rates than HA. However, during the prevalence of H3N2 CIV in China, the fact that a prominent sequence change was found in NA and not HA may indicate that this 2-aa insertion plays an important role in virus infectivity in dogs. However, as no genome sequences of H3N2 CIV from South Korea have been deposited in GenBank since 2013, we do not know whether the NA insertion has occurred yet in that country.

When AIV are transmitted from water fowl to poultry, they undergo genetic modifications that correlate with higher virulence and broader host range. Common 


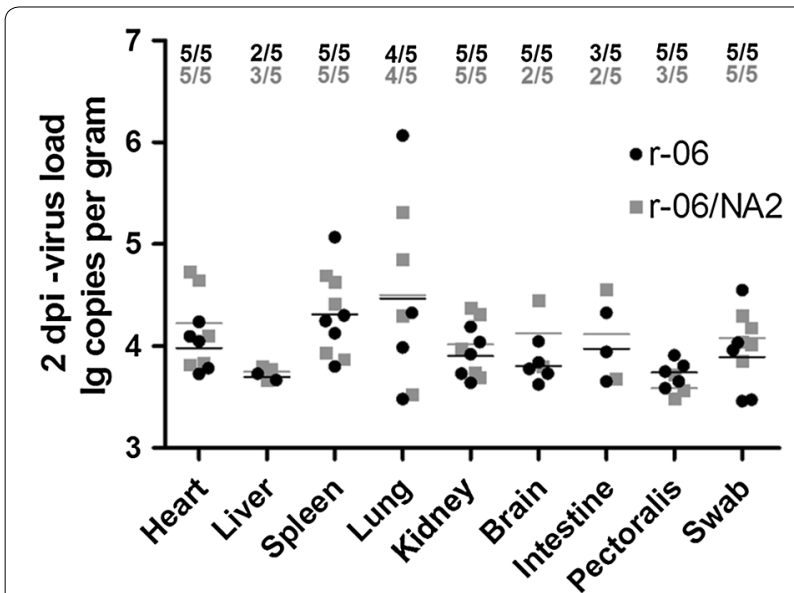

Figure 10 Viral RNA loads in some tissues and swabs of chickens inoculated with r-06 (O) and r-06/NA2 ( ) strains at 2 dpi. Five chickens were chosen randomly and euthanized from each group. Each dot represents viral RNA load in an organ sample from one chicken. Viral loads are expressed as log10 RNA copy numbers per gram of sample.

genetic AIV mutations in viral proteins of poultry isolates are deletions in the stalk region of the NA and additions of glycosylation sites on HA [16]. These observations raise the question of whether the short NA stalk is more suitable for transmission of AIV to mammals. A recent study demonstrated that a further restriction to mammalian transmission of the majority of highly pathogenic avian influenza (HPAI) H5N1 viruses may be the short stalk length of the NA protein [23]. Therefore, we presume that the elongation of the NA stalk by 2 aa in nature may facilitate more efficient transmission of avian-origin H3N2 CIV in dog populations.
NA function, which is critical to virus release [7], may also act independently to determine the overall robustness of influenza virus and directly influence viral yield [24]. Previous studies reported that inserting at least more than 20 aa into the middle region of NA stalks can significantly increase the viral yield in both embryonated chicken eggs and MDCK cells $[25,26]$. In our study, just a 2-aa insertion at the distal end of the NA stalk could lead to increased viral yield in MDCK, CEF and CBE cell cultures. In CEF and CBE cells, r-06 strain reached the peak viral titer earlier than the $r-06 / N A 2$ strain, which may be due to the fact that the 2-aa insertion facilitated the NA-mediated release of virus during budding from cells, thereby allowing the virus to infect neighboring cells more quickly and thus reach the peak titer earlier. In addition, in MDCK and CEF cells, after peak viral titers were reached, r-06/NA2 exhibited a continuous decreasing trend, whereas $\mathrm{r}-06$ viral titer slightly increased from 60 to $72 \mathrm{~h}$. This discrepancy may suggest that viable progeny viruses could still be produced in r-06 infected cells but fewer or not in r-06/NA2 infected cells at the late stage of infection. In MDCK, CEF and CBE cells, the mean fluorescence intensity of NS1 expression with $\mathrm{r}-06$ infection was significantly higher than that with $\mathrm{r}-06 / \mathrm{NA} 2$ infection. This observation suggests that more progeny viruses were assembled in one single cell infected with long stalk virus. It is worth mentioning that in CBE cells, the two viral strains had similar infection rates at $24 \mathrm{~h}$ after inoculation, but the NS1 expression of $\mathrm{r}-06$ was remarkably higher than that of $\mathrm{r}-06 / \mathrm{NA} 2$. This phenomenon presented here indicates that although the two viral strains infected the similar number of cells, the r-06 strain may replicate more efficiently in target cells.
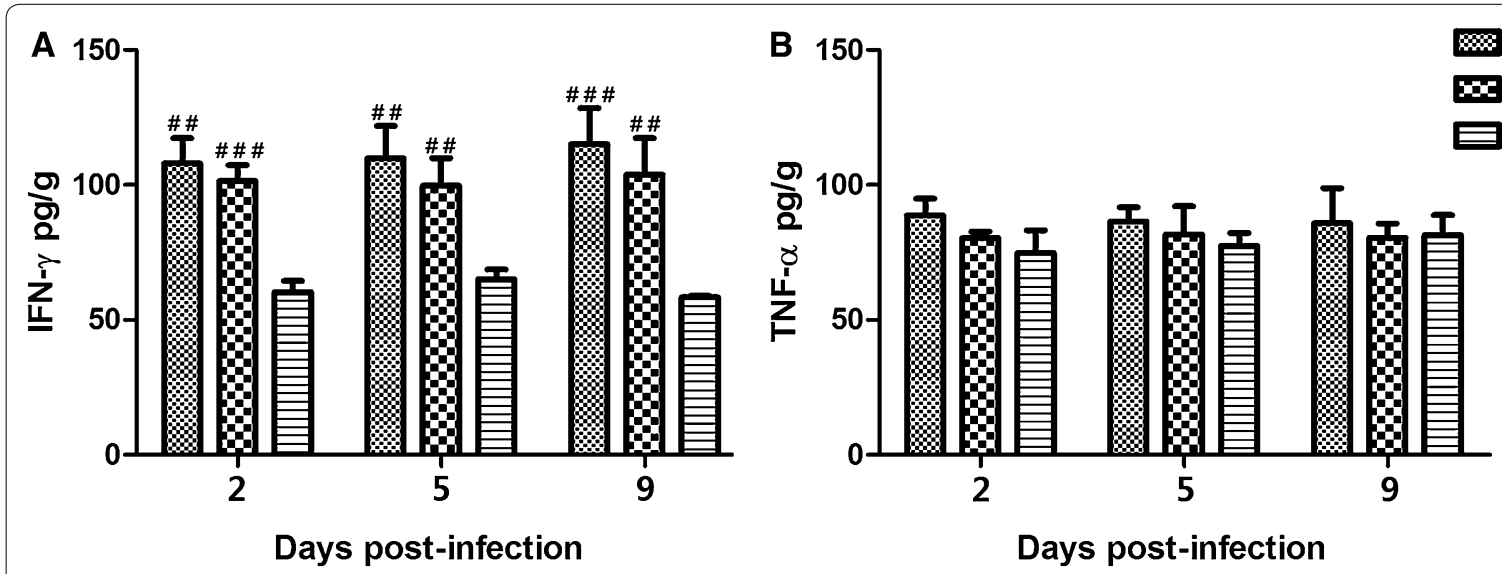

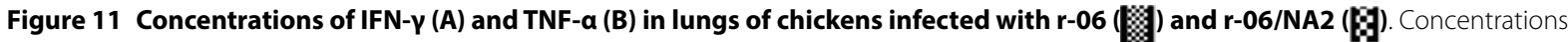
of cytokines were determined via ELISA in lung supernatants taken from different days after infection. The results are expressed in terms of pg/ $\mathrm{g}$. ${ }^{\#} P<0.05,{ }^{\#} P<0.01$, or ${ }^{\# \# \#} P<0.005$ indicates a significant difference between the infected groups and the PBS control group. 
The insertion increased virus infectivity and virulence not only in cell cultures but also in mice. Compared to r-06/NA2-infected mice, r-06-infected mice had higher viral RNA titers and more viral staining in the lung, spleen and brain at $6 \mathrm{dpi}$, higher frequencies of viral RNA-positive tissues at $8 \mathrm{dpi}$, and more severe lesions in the lung. The study from Matsuoka et al. [27] reported the contradictory observation that virulence in mice was enhanced for viruses with a truncated NA stalk compared to their equivalents with a long stalk. The conflicting results may be explained by the possibility that virulence is not due to the length of the NA stalk but rather to a new stalk motif constructed after the insertion or deletion of amino acids. Zhou et al. [28] concluded that a unique NA stalk motif is responsible for increased virulence and pathogenesis in mice, since neither an insertion nor deletion of aa in the NA stalk increased the virulence compared to the wild-type viral strain. Nevertheless, the insertion strain showed higher infectivity in MDCK cells and mice than the deletion strain, consistent with our findings. The decreased virulence of $\mathrm{r}-06 / \mathrm{NA} 2$ in mice may be attributed to the fact that a short-stalk NA is less competent in desialating the mucus barrier in the respiratory tract. Some previous studies $[16,23]$ demonstrated that a virus with a short NA stalk had a reduced ability to initiate infection in the presence of mucus, and neutralization of virus by mucus was significantly reduced through extending the NA stalk length. Influenza viruses require a careful balance of HA and NA activity in order to adapt to their hosts. Deletion of the NA stalk is often coupled with increased HA glycosylation as a compensation, which has been shown to reduce receptor binding affinity [29-32]. However, sequence analysis of H3N2 CIV strains with additional residues inserted in NA but no new common mutations in HA indicate that the increased infectivity by elongation of NA is independent of HA function. Our study shows that the CIV strain with elongated NA had increased virulence in mice with a more rapid and higher level of local IFN- $\gamma$ response. An elevated level of IFN- $\gamma$ observed in $r-06$-infected mice at 2 and 8 dpi may appropriately reflect the faster replication of the virus at this early period of infection. However, no obvious difference in TNF- $\alpha$ level was found between these two virus groups at this time. Sandbulte et al. [33] also found that differences in TNF- $\alpha$ induction by different viruses were less pronounced than those in interferon induction. A study from Seo and Webster [34] reported that TNF- $\alpha$ exhibited greater antiviral effects to counteract influenza virus infection than IFN- $\gamma$. Thus, although $r-06 /$ NA2 replicated more slowly, it could still trigger a high level of TNF- $\alpha$ as did $r-06$.
A shortened NA stalk has been reported to be a strong determinant of the adaptation and virulence of water fowl influenza viruses in chickens $[16,17]$. Thus, the question arises as to whether the avian-origin H3N2 CIV with a 2-aa insertion in the NA stalk can adapt and increase virulence in chickens. However, our experimental infection in chickens shows the two viruses exhibited no obvious differences in body weight loss, viral loads of tissues and swabs, and levels of IFN- $\gamma$ and TNF- $\alpha$. We presume that the 2-aa insertion is not favorable for replication or transmission of H3N2 AIV in chickens. However, the insertion may lead to either a better transmission or higher virulence of H3N2 CIV in dogs, since the NA of AIV did not mutate and increase in length during many years in circulation until the interspecies transmission of H3N2 AIV to dogs and spread in China.

Notably, the viral load in chickens was lower than that in mice. This reduction in viral load may be caused by mutations in receptor binding sites, antigenic sites and/ or glycosylation cleavage sites in HA [12]. These mutations may lead to H3N2 AIV that are not suitable for replication in chickens. In summary, this report showed that the 2-aa insertion at the distal end of the NA stalk region of $\mathrm{H} 3 \mathrm{~N} 2 \mathrm{CIV}$ could give rise to viruses that replicated more efficiently in MDCK, CEF and CBE cells and were more pathogenic in mice. These findings suggest that H3N2 CIV acquired an insertional mutation in NA and consequently achieved enhanced transmission to dogs. Multigenic adaptation facilitated H3N2 influenza viruses in overcoming the host species barrier and causing pandemics in dogs. As these viruses continue to evolve while spreading geographically, better surveillance and control strategies for the viral disease in companion animals should be developed.

\section{Competing interests \\ The authors declare that they have no competing interests.}

\section{Author details}

${ }^{1}$ College of Veterinary Medicine, Nanjing Agricultural University, Nanjing 210095, China. ${ }^{2}$ College of Animal Science and Technology, Nanjing Agricultural University, Nanjing 210095, China.

\section{Authors' contributions}

$Y L$ carried out most of the experiments described in the manuscript and wrote the article; $X X$, participated in the design of the study and performed the statistical analysis; $Y Z, D H K, C L$ helped with the animal experiments. $Y L$ conceived the study and contributed in its design and coordination. All authors read and approved the final manuscript.

\section{Acknowledgements}

This work was supported by the International S\&T Cooperation Program of China (2014DFG32770) and Priority Academic Program Development of Jiangsu Higher Education Institutions (PAPD).

Received: 27 October 2015 Accepted: 14 March 2016

Published online: 09 May 2016 


\section{References}

1. Webster RG (1998) Influenza: an emerging disease. Emerg Infect Dis 4:436-441

2. Crawford PC, Dubovi EJ, Castleman WL, Stephenson I, Gibbs EP, Chen L, Smith C, Hill RC, Ferro P, Pompey J, Bright RA, Medina MJ, Johnson CM, Olsen CW, Cox NJ, Klimov Al, Katz JM, Donis RO (2005) Transmission of equine influenza virus to dogs. Science 310:482-485

3. Song D, Kang B, Lee C, Jung K, Ha G, Kang D, Park S, Park B, Oh J (2008) Transmission of avian influenza virus (H3N2) to dogs. Emerg Infect Dis 14:741-746

4. Song D, Lee C, Kang B, Jung K, Oh T, Kim H, Park B, Oh J (2009) Experimental infection of dogs with avian-origin canine influenza A virus (H3N2) Emerg Infect Dis 15:56-58

5. Lee C, Song D, Kang B, Kang D, Yoo J, Jung K, Na G, Lee K, Park B, Oh J (2009) A serological survey of avian origin canine H3N2 influenza virus in dogs in Korea. Vet Microbiol 137:359-362

6. Su S, Chen Y, Zhao FR, Chen JD, Xie JX, Chen ZM, Huang Z, Hu YM, Zhang MZ, Tan LK, Zhang GH, Li SJ (2013) Avian-origin H3N2 canine influenza virus circulating in farmed dogs in Guangdong, China. Infect Genet Evol 19:251-256

7. Palese P, Tobita K, Ueda M, Compans RW (1974) Characterization of temperature sensitive influenza virus mutants defective in neuraminidase. Virology 61:397-410

8. Rogers GN, Paulson JC (1983) Receptor determinants of human and animal influenza virus isolates: differences in receptor specificity of the $\mathrm{H} 3$ hemagglutinin based on species of origin. Virology 127:361-373

9. Luo G, Chung J, Palese P (1993) Alterations of the stalk of the influenza virus neuraminidase: deletions and insertions. Virus Res 29:141-153

10. Lu B, Zhou H, Ye D, Kemble G, Jin H (2005) Improvement of influenza A Fujian/411/02 (H3N2) virus growth in embryonated chicken eggs by balancing the hemagglutinin and neuraminidase activities, using reverse genetics. J Virol 79:6763-6771

11. Wagner R, Matrosovich M, Klenk HD (2002) Functional balance between haemagglutinin and neuraminidase in influenza virus infections. Rev Med Virol 12:159-166

12. Lin Y, Zhao Y, Zeng X, Lu C, Liu Y (2012) Genetic and pathobiologic characterization of H3N2 canine influenza viruses isolated in the Jiangsu Province of China in 2009-2010. Vet Microbiol 158:247-258

13. Teng Q, Zhang X, Xu D, Zhou J, Dai X, Chen Z, Li Z (2013) Characterization of an $\mathrm{H} 3 \mathrm{~N} 2$ canine influenza virus isolated from Tibetan mastiffs in China. Vet Microbiol 162:345-352

14. Sun Y, Sun S, Ma J, Tan Y, Du L, Shen Y, Mu Q, Pu J, Lin D, Liu J (2013) Identification and characterization of avian-origin H3N2 canine influenza viruses in northern China during 2009-2010. Virology 435:301-307

15. Bunpapong N, Nonthabenjawan N, Chaiwong S, Tangwangvivat R, Boonyapisitsopa S, Jairak W, Tuanudom R, Prakairungnamthip D, Suradhat S, Thanawongnuwech R, Prakairungnamthip D, Suradhat S, Thanawongnuwech R, Amonsin A (2014) Genetic characterization of canine influenza A virus (H3N2) in Thailand. Virus Genes 48.56-63

16. Li J, Zu Dohna H, Cardona CJ, Miller J, Carpenter TE (2011) Emergence and genetic variation of neuraminidase stalk deletions in avian influenza viruses. PLoS One 6:e14722

17. Munier S, Larcher T, Cormier-Aline F, Soubieux D, Su B, Guigand L, Labrosse B, Cherel Y, Quere P, Marc D, Naffakh N (2010) A genetically engineered waterfowl influenza virus with a deletion in the stalk of the neuraminidase has increased virulence for chickens. J Virol 84:940-952

18. Jin DP, Li CY, Yang HJ, Zhang WX, Li CL, Guan WJ, Ma YH (2011) Apoptotic effects of hydrogen peroxide and vitamin C on chicken embryonic fibroblasts: redox state and programmed cell death. Cytotechnology 63:461-471

19. Xie X, Pang M, Liang S, Yu L, Zhao Y, Ma K, Kalhoro DH, Lu C, Liu Y (2015) Establishment and characterization of a telomerase-immortalized canine bronchiolar epithelial cell line. Appl Microbiol Biotechnol 99:9135-9146

20. Li Z, Chen H, Jiao P, Deng G, Tian G, Li Y, Hoffmann E, Webster RG, Matsuoka Y, Yu K (2005) Molecular basis of replication of duck H5N1 influenza viruses in a mammalian mouse model. J Virol 79:12058-12064
21. Walker RA (2006) Quantification of immunohistochemistry-issues concerning methods, utility and semiquantitative assessment I. Histopathology 49:406-410

22. Murakami S, Horimoto T, le Mai Q, Nidom CA, Chen H, Muramoto Y, Yamada S, Iwasa A, Iwatsuki-Horimoto K, Shimojima M, Iwata A, Kawaoka Y (2008) Growth determinants for H5N1 influenza vaccine seed viruses in MDCK cells. J Virol 82:10502-10509

23. Blumenkrantz D, Roberts KL, Shelton H, Lycett S, Barclay WS (2013) The short stalk length of highly pathogenic avian influenza H5N1 virus neuraminidase limits transmission of pandemic H1N1 virus in ferrets. J Virol 87:10539-10551

24. Matrosovich MN, Matrosovich TY, Gray T, Roberts NA, Klenk HD (2004) Neuraminidase is important for the initiation of influenza virus infection in human airway epithelium. J Virol 78:12665-12667

25. Zhang W, Xue T, Wu X, Zhang P, Zhao G, Peng D, Hu S, Wang X, Liu X, Liu W, Liu X (2011) Increase in viral yield in eggs and MDCK cells of reassortant $\mathrm{H} 5 \mathrm{~N} 1$ vaccine candidate viruses caused by insertion of 38 amino acids into the NA stalk. Vaccine 29:8032-8041

26. Adamo JE, Liu T, Schmeisser F, Ye Z (2009) Optimizing viral protein yield of influenza virus strain A/Vietnam/1203/2004 by modification of the neuraminidase gene. J Virol 83:4023-4029

27. Matsuoka Y, Swayne DE, Thomas C, Rameix-Welti MA, Naffakh N, Warnes C, Altholtz M, Donis R, Subbarao K (2009) Neuraminidase stalk length and additional glycosylation of the hemagglutinin influence the virulence of influenza H5N1 viruses for mice. J Virol 83:4704-4708

28. Zhou H, Yu Z, Hu Y, Tu J, Zou W, Peng Y, Zhu J, Li Y, Zhang A, Yu Z, Ye Z, Chen $\mathrm{H}$, Jin M (2009) The special neuraminidase stalk-motif responsible for increased virulence and pathogenesis of H5N1 influenza A virus. PLoS One 4:e6277

29. Matrosovich M, Zhou N, Kawaoka Y, Webster R (1999) The surface glycoproteins of H5 influenza viruses isolated from humans, chickens, and wild aquatic birds have distinguishable properties. J Virol 73:1146-1155

30. Bender C, Hall H, Huang J, Klimov A, Cox N, Hay A, Gregory V, Cameron K, Lim W, Subbarao K (1999) Characterization of the surface proteins of influenza A (H5N1) viruses isolated from humans in 1997-1998. Virology 254:115-123

31. Banks J, Speidel ES, Moore E, Plowright L, Piccirillo A, Capua I, Cordioli P, Fioretti A, Alexander DJ (2001) Changes in the haemagglutinin and the neuraminidase genes prior to the emergence of highly pathogenic H7N1 avian influenza viruses in Italy. Arch Virol 146:963-973

32. Baigent SJ, McCauley JW (2001) Glycosylation of haemagglutinin and stalk-length of neuraminidase combine to regulate the growth of avian influenza viruses in tissue culture. Virus Res 79:177-185

33. Sandbulte MR, Boon AC, Webby RJ, Riberdy JM (2008) Analysis of cytokine secretion from human plasmacytoid dendritic cells infected with $\mathrm{H} 5 \mathrm{~N} 1$ or low-pathogenicity influenza viruses. Virology 381:22-28

34. Seo SH, Webster RG (2002) Tumor necrosis factor alpha exerts powerful anti-influenza virus effects in lung epithelial cells. J Virol 76:1071-1076

\section{Submit your next manuscript to BioMed Central and we will help you at every step:}

- We accept pre-submission inquiries

- Our selector tool helps you to find the most relevant journal

- We provide round the clock customer support

- Convenient online submission

- Thorough peer review

- Inclusion in PubMed and all major indexing services

- Maximum visibility for your research

Submit your manuscript at www.biomedcentral com/submit 